\title{
Capacitation in the presence of methyl- $\beta$-cyclodextrin results in enhanced zona pellucida-binding ability of stallion spermatozoa
}

\author{
Elizabeth G Bromfield, R John Aitken, Zamira Gibb, Sarah R Lambourne and Brett Nixon \\ School of Environmental and Life Sciences, Priority Research Centre for Reproductive Biology, Discipline of \\ Biological Sciences, University of Newcastle, Callaghan, New South Wales 2308, Australia
}

Correspondence should be addressed to B Nixon; Email: brett.nixon@newcastle.edu.au

\begin{abstract}
While IVF has been widely successful in many domesticated species, the development of a robust IVF system for the horse remains an elusive and highly valued goal. A major impediment to the development of equine IVF is the fact that optimised conditions for the capacitation of equine spermatozoa are yet to be developed. Conversely, it is known that stallion spermatozoa are particularly susceptible to damage arising as a consequence of capacitation-like changes induced prematurely in response to semen handling and transport conditions. To address these limitations, this study sought to develop an effective system to both suppress and promote the in vitro capacitation of stallion spermatozoa. Our data indicated that the latter could be achieved in a bicarbonate-rich medium supplemented with a phosphodiesterase inhibitor, a cyclic AMP analogue, and methyl- $\beta$-cyclodextrin, an efficient cholesterolwithdrawing agent. The populations of spermatozoa generated under these conditions displayed a number of hallmarks of capacitation, including elevated levels of tyrosine phosphorylation, a reorganisation of the plasma membrane leading to lipid raft coalescence in the peri-acrosomal region of the sperm head, and a dramatic increase in their ability to interact with heterologous bovine zona pellucida (ZP) and undergo agonist-induced acrosomal exocytosis. Furthermore, this functional transformation was effectively suppressed in media devoid of bicarbonate. Collectively, these results highlight the importance of efficient cholesterol removal in priming stallion spermatozoa for ZP binding in vitro.

Reproduction (2014) 147 153-166
\end{abstract}

\section{Introduction}

In contrast to the considerable IVF successes that have been achieved in other mammalian species such as mice (Whittingham 1968, Mukherjee \& Cohen 1970) and cattle (Iritani \& Niwa 1977, Brackett et al. 1982), the development of a robust IVF system for equine species remains difficult; only two foals having been reported using conventional IVF protocols (Palmer et al. 1991, Bezard 1992). The fundamental impediments, which are at least partly responsible for the slow progression of equine IVF, include the limited availability of equine oocytes and the slow development of in vitro oocyte maturation. However, a compounding factor that is yet to be satisfactorily addressed is the low efficiency of methods for the capacitation of stallion spermatozoa in vitro (Blue et al. 1989, Alm et al. 2001).

Previous attempts to achieve stallion sperm capacitation in vitro have resulted in low sperm penetration rates of equine oocytes during IVF (Zhang et al. 1990), low phosphotyrosine levels (Ellington et al. 1993) and low rates of agonist-induced acrosomal exocytosis (Christensen et al. 1996). Heparin and TALP-HEPES medium or modifications of Krebs-Ringer bicarbonate have often been used to capacitate equine spermatozoa for IVF as they can promote reproducible responses in these cells (Dell' Aquila et al. 1996, Choi et al. 2003, Clulow et al. 2010). Notwithstanding their reproducibility, these capacitation media are not able to promote levels of acrosomal exocytosis or protein tyrosine phosphorylation that are comparable to those achieved in the spermatozoa of other species such as cattle (Galantino-Homer et al. 2004, Purdy \& Graham 2004) or humans (Lu et al. 2006).

Recent work carried out by McPartlin et al. (2008) indicated that a defined medium containing $25 \mathrm{mM}$ bicarbonate and $7 \mathrm{mg} / \mathrm{ml}$ BSA could promote high levels of protein tyrosine phosphorylation and acrosomal exocytosis in stallion spermatozoa after $4 \mathrm{~h}$ of incubation at $37^{\circ} \mathrm{C}$ (McPartlin et al. 2008). Such conditions are similar to those required for the capacitation of murine sperm (Visconti et al. 1995a) and may partially explain the limited success of previously developed stallion sperm capacitation media that were largely modelled on the requirements of bovine spermatozoa (Chamberland et al. 2001). González-Fernández et al. (2012) have also recently shown that the capacitation of stallion spermatozoa 
in an air atmosphere (as opposed to $5 \% \mathrm{CO}_{2}$ ) promotes a remarkable up-regulation of protein tyrosine phosphorylation to levels comparable to those attained in the studies of McPartlin et al. (2008). Such changes appear to be attributed to a loss of the bicarbonate buffering effect and hence an elevation in the $\mathrm{pH}$ of the medium (González-Fernández et al. 2012). However, the ability of spermatozoa capacitated under these conditions to interact with oocytes is yet to be determined.

Despite these important findings, a key limitation of these optimisation studies is their reliance upon the supplementation of capacitation media with serum albumin (Rathi et al. 2003, McPartlin et al. 2008, 2011). The inclusion of albumin is attributed to its unique ability to sequester membrane sterols, such as cholesterol (Boerke et al. 2008), and cytotoxic lipid peroxides (Alvarez \& Storey 1983). While bicarbonate and calcium fluxes are required for rapid CAMP production and increases in membrane fluidity (Harrison et al. 1993), albumin-mediated sterol depletion is critical to achieve increases in protein tyrosine phosphorylation, often considered a hallmark of sperm functional competence in model species such as the mouse (Visconti et al. 1995b, Galantino-Homer et al. 1997). Sterol loss occurs either through the contribution of an active cholesterol transporter that provides free cholesterol to the hydrophobic pocket of albumin (Flesch et al. 2001) or possibly through the oxidation of membrane sterols and the subsequent scavenging of the hydrophilic oxidation products by albumin (Boerke et al. 2013). Understandably, BSA is a reliable macromolecule to facilitate cholesterol loss in stallion sperm (Rathi et al. 2003, McPartlin et al. 2008); nevertheless, if a capacitation medium is to be used regularly in equine assisted reproduction, an alternative macromolecule of nonanimal origin would be required due to the legitimate concern of zoonotic disease transmission and to ensure the reproducibility of the media.

Somewhat paradoxically, another limitation associated with assisted reproduction is the premature induction of capacitation-like changes associated with semen transport (Bailey \& Buhr 1994). The cellular destabilisation and reduced longevity that accompany such changes (Bailey et al. 2000) are potentially extremely problematic, given that semen may need to be transported a considerable distance between the sites of collection and usage. Such effects are usually ameliorated by the dilution of the semen sample in an extender solution immediately after collection. However, such extenders are also typically formulated to include animal-derived products (Kenney et al. 1975), and systematic studies of their impact on equine sperm function are currently lacking. Consequently, the aims of this study were to design optimal conditions for both the suppression and promotion of equine sperm capacitation in the absence of animal-derived supplements.
These aims were achieved through two experimental approaches. The first of these evaluated the hypothesis that a non-capacitating (NC) formulation of media could be used to effectively limit capacitation-like membrane modifications during semen transport. The second tested the hypothesis that the addition of an artificial cholesterol-withdrawing agent, methyl- $\beta$-cyclodextrin $(\mathrm{m} \beta \mathrm{cd})$, could increase the efficacy of stallion sperm capacitation in vitro.

\section{Materials and methods}

\section{Chemicals and reagents}

Unless specified, research-grade chemical reagents were obtained from Sigma. The following conjugated antibodies were purchased to characterise proteins of interest: antiphosphotyrosine (PT66-FITC) and anti-phosphotyrosine (PT66-HRP). SYTOX Green cell vitality stain was purchased from Invitrogen. Anti-mouse IgG-HRP was obtained from Upstate Biotechnology (Lake Placid, NY, USA). HEPES, penicillin, and streptomycin were obtained from Invitrogen. BSA was obtained from Research Organics (Cleveland, $\mathrm{OH}$, USA). Minicomplete protease inhibitor mixture tablets were purchased from Roche Applied Science. Nitrocellulose membranes were obtained from GE Healthcare (Piscataway, NJ, USA). Mowiol 4-88 was obtained from Calbiochem (La Jolla, CA, USA), and paraformaldehyde was supplied by ProSciTech (Thuringowa, Qld, Australia).

\section{Collection and preparation of equine spermatozoa}

Animals were used with the authorisation of the University of Newcastle animal care and ethics committee (A-2011-122). Semen was collected with an open-ended artificial vagina from three adult pony stallions of proven fertility as described previously (Aitken et al. 2012). Raw semen was filtered into a sterile collection container and diluted 2:1 in pre-warmed Kenney's extender (Kenney et al. 1975), consisting of $133 \mathrm{mM}$ D-glucose, $4.9 \%$ (w/v) skimmed milk powder, $2.8 \mathrm{mM}$ Penicillin $\mathrm{G}$ sodium salt, and $2.1 \mathrm{mM}$ streptomycin sulphate salt. Alternatively, semen was diluted $2: 1$ in a modified NC form of Biggers, Whitten and Whittingham medium (NC BWW; Biggers et al. 1971), composed of $91.5 \mathrm{mM} \mathrm{NaCl}, 4.6 \mathrm{mM} \mathrm{KCl}, 1.7 \mathrm{mM} \mathrm{CaCl} 2 \cdot 2 \mathrm{H}_{2} \mathrm{O}$, $1.2 \mathrm{mM} \mathrm{KH}_{2} \mathrm{PO}_{4}, 1.2 \mathrm{mM} \mathrm{MgSO} \cdot \cdot 7 \mathrm{H}_{2} \mathrm{O}, 5.6 \mathrm{mM}$ D-glucose, $0.27 \mathrm{mM}$ sodium pyruvate, $44 \mathrm{mM}$ sodium lactate, $5 \mathrm{U} / \mathrm{ml}$ penicillin, $5 \mathrm{mg} / \mathrm{ml}$ streptomycin, and $20 \mathrm{mM}$ HEPES buffer (osmolarity of $300 \mathrm{mOsm} / \mathrm{kg}$ ). Samples were transported to the laboratory at $\sim 37^{\circ} \mathrm{C}$ in an insulated container within $1 \mathrm{~h}$ of ejaculation. Viable spermatozoa were recovered from these samples through use of a 40 and $80 \%$ discontinuous Percoll (GE Healthcare) gradient as described for human spermatozoa (Aitken et al. 2003). Stallion spermatozoa were then pelleted by centrifugation at $500 \mathrm{~g}$ for a further $15 \mathrm{~min}$ at room temperature and resuspended at a concentration of $10 \times 10^{6}$ cells $/ \mathrm{ml}$ in NC BWW medium before being used for all assays. Additionally, for experiment 1, raw (Percoll-free) sperm samples were prepared by removing the transport 
extender through a single centrifugation step at $500 \boldsymbol{g}$ for $15 \mathrm{~min}$, after which the pelleted stallion spermatozoa were diluted to a concentration of $10 \times 10^{6}$ cells $/ \mathrm{ml}$ in NC BWW medium.

\section{Capacitation of stallion spermatozoa}

After Percoll fractionation, enriched spermatozoa were recovered from the base of the $80 \%$ Percoll fraction and resuspended in Biggers, Whitten and Whittingham medium, composed of $91.5 \mathrm{mM} \mathrm{NaCl}, 4.6 \mathrm{mM} \mathrm{KCl}, 1.7 \mathrm{mM} \mathrm{CaCl} 2 \cdot 2 \mathrm{H}_{2} \mathrm{O}$, $1.2 \mathrm{mM} \mathrm{KH}_{2} \mathrm{PO}_{4}, 1.2 \mathrm{mM} \mathrm{MgSO} \cdot \cdot 7 \mathrm{H}_{2} \mathrm{O}, 25 \mathrm{mM} \mathrm{NaHCO}$, $5.6 \mathrm{mM}$ D-glucose, $0.27 \mathrm{mM}$ sodium pyruvate, $44 \mathrm{mM}$ sodium lactate, $5 \mathrm{U} / \mathrm{ml}$ penicillin, $5 \mathrm{mg} / \mathrm{ml}$ streptomycin, $20 \mathrm{mM} \mathrm{HEPES}$ buffer, and $1 \mathrm{mg} / \mathrm{ml}$ polyvinyl alcohol (PVA) (87-90\% hydrolysed, average MW 30 000-70 000) (osmolarity of $300 \mathrm{mOsm} / \mathrm{kg}$ ), at a concentration of $10 \times 10^{6} \mathrm{cells} / \mathrm{ml}$. The formulation of the different capacitation media used in this study is given in Table 1. Populations of capacitated spermatozoa were prepared by incubation at $37{ }^{\circ} \mathrm{C}$ under an atmosphere of $5 \%$ $\mathrm{CO}_{2}$ and $95 \%$ air for up to $18 \mathrm{~h}$. At regular intervals throughout the incubation, sperm suspensions were gently mixed to prevent settling of the cells.

\section{Computer-assisted sperm analysis}

Stallion sperm motility analysis was conducted at $37^{\circ} \mathrm{C}$ using a HTM-IVOS CASA system (Hamilton-Thorne Biosciences, Beverly, MA, USA; version 12.3) and chamber slides of $20 \mu \mathrm{m}$ depth (Leja, Nieuw-Vennep, The Netherlands). The following sperm parameters were analysed: total motility (\%), forward progressive motility (\%), amplitude of lateral head displacement $(\mathrm{ALH} ; \mu \mathrm{m})$, and track speed $(\mu \mathrm{m} / \mathrm{s})$. HTM-IVOS software settings were adjusted for equine sperm as follows: 60 frames/s, 30 frames acquired, minimum contrast 70, minimum cell size 4pix, and VAP cut-off $20.0 \mu \mathrm{m} / \mathrm{s}$.

\section{Cholesterol efflux}

MC540 (Sigma) and filipin (Sigma) were used to assess membrane fluidity and cholesterol distribution respectively. After transport to the laboratory in NC BWW medium or Kenney's extender and Percoll fractionation (unless otherwise specified), an aliquot of stallion sperm was diluted to $1 \times 10^{6} \mathrm{cell} / \mathrm{s} / \mathrm{ml}$ and incubated in SYTOX Green cell vitality stain at $37^{\circ} \mathrm{C}$ for $10 \mathrm{~min}$. This preparation was washed once with BWW medium and then split and incubated in either
$25 \mu \mathrm{m}$ filipin at $37^{\circ} \mathrm{C}$ for 30 min or $2.7 \mu \mathrm{m} \mathrm{MC540} \mathrm{at} 37^{\circ} \mathrm{C}$ for $10 \mathrm{~min}$. Preparations were then washed once with BWW medium, and 200 cells from each treatment were scored on a Zeiss fluorescence microscope at excitation wavelengths of $590 \mathrm{~nm}$ (MC540), $470 \mathrm{~nm}$ (SYTOX Green), and 365 nm (filipin) (Carl Zeiss, Thornwood, NY, USA). Merocyanine-positive sperm were identified through bright red fluorescence over the entire head and the absence of SYTOX Green staining and filipin-stained sperm were classified as filipin positive when blue fluorescence was present over the peri-acrosomal region of the sperm head, but absent from the post-acrosomal region.

\section{SDS-PAGE and immunoblotting}

Following treatment, spermatozoa were pelleted via centrifugation and resuspended for protein extraction as described previously (Reid et al. 2012). Protein extracts were then boiled in the presence of NuPAGE LDS sample buffer (Invitrogen) containing $8 \% \beta$-mercaptoethanol, subjected to SDS-PAGE using $4-12 \%$ BIS-TRIS gels (Invitrogen) and then electrotransferred onto nitrocellulose membranes using conventional western blotting techniques (Towbin et al. 1979). To detect proteins of interest, the membranes were blocked in $3 \% \mathrm{w} / \mathrm{v}$ BSA in Tris-buffered saline supplemented with $0.1 \%$ Tween 20 (TBST, pH 7.4) and then probed with HRP-conjugated antiphosphotyrosine antibody ( $\alpha$-PT66) diluted 1:10 000 in TBST supplemented with $1 \%$ BSA under constant rotation for $1 \mathrm{~h}$ at room temperature. The membranes were washed with TBST $(3 \times 10 \mathrm{~min})$, and proteins were visualised using an $\mathrm{ECL}$ detection kit (ECL plus, Amersham Bioscience) according to the manufacturer's instructions.

\section{Immunocytochemistry on fixed spermatozoa}

Following capacitation, spermatozoa were fixed in $4 \%$ paraformaldehyde, washed three times with $0.05 \mathrm{M}$ glycine in PBS and then applied to poly-L-lysine-coated glass coverslips. The cells were permeabilised in a humid chamber with $0.2 \%$ Triton X-100 and blocked in 3\% BSA/PBS for $1 \mathrm{~h}$. The coverslips were then washed with PBS and incubated with $\alpha$-PT66conjugated FITC antibody to phosphotyrosine diluted 1:100 with $1 \% \mathrm{BSA} / \mathrm{PBS}$ for $1 \mathrm{~h}$ at $37^{\circ} \mathrm{C}$. Following this, the coverslips were washed $(3 \times 5 \mathrm{~min})$ with filtered PBS before mounting in $10 \%$ Mowiol 4-88 (Calbiochem) with $30 \%$ glycerol in $0.2 \mathrm{M}$ Tris (pH 8.5) and 2.5\% 1,4-diazabicyclo-(2.2.2)-octane (DABCO). Stallion spermatozoa were examined with a Zeiss LSM510 laser scanning confocal microscope (Carl Zeiss Pty, Sydney, Australia).

Table 1 Formulation of media used for the capacitation of stallion spermatozoa.

\begin{tabular}{|c|c|c|c|c|c|c|c|c|c|c|}
\hline Ingredients & $\begin{array}{c}\text { NC } \\
\text { BWW }\end{array}$ & $\begin{array}{c}\text { Bic } \\
\text { (PVA) }\end{array}$ & $\begin{array}{l}\text { CAP } \\
\text { (PVA) }\end{array}$ & $\begin{array}{l}\text { PVA+ } \\
\text { m } \beta \mathbf{c d}\end{array}$ & $\begin{array}{c}\text { Bic } \\
(B S A)\end{array}$ & $\begin{array}{l}\text { CAP } \\
\text { (BSA) }\end{array}$ & $\begin{array}{l}\mathrm{BSA}+ \\
\mathrm{m} \beta \mathrm{cd}\end{array}$ & $\begin{array}{c}\text { Bic } \\
(\mathrm{SB})\end{array}$ & $\begin{array}{l}\text { CAP } \\
(\mathrm{SB})\end{array}$ & $\begin{array}{l}\mathrm{SB}+ \\
\mathrm{m} \beta \mathbf{c d}\end{array}$ \\
\hline $\mathrm{NaHCO}_{3}(\mathrm{mM})$ & - & 25 & 25 & 25 & 25 & 25 & 25 & 25 & 25 & 25 \\
\hline $\mathrm{NaCl}(\mathrm{mM})$ & 25 & - & - & - & - & - & - & - & - & - \\
\hline $\mathrm{BSA}(\mathrm{mg} / \mathrm{ml})$ & - & - & - & - & 3 & 3 & 3 & - & - & - \\
\hline PVA (mg/ml) & - & 1 & 1 & 1 & - & - & - & - & - & - \\
\hline Soybean hydrolysate (SB; mg/ml) & - & - & - & - & - & - & - & 1.2 & 1.2 & 1.2 \\
\hline $\mathrm{m} \beta \mathrm{cd}(\mathrm{mM})$ & - & - & - & 0.5 & - & - & 0.5 & - & - & 0.5 \\
\hline Pentoxifylline (mM) & - & - & 3 & 3 & - & 3 & 3 & - & 3 & 3 \\
\hline Dibutyryl cyclic AMP (mM) & - & - & 5 & 5 & - & 5 & 5 & - & 5 & 5 \\
\hline
\end{tabular}




\section{Equine follicular fluid extraction}

To obtain equine follicular fluid (FF), post-mortem ovaries were obtained from a local slaughterhouse and transported to the laboratory on ice. Ovaries were washed with $0.9 \% \mathrm{NaCl}$ and adnexa were trimmed. Visible follicles were punctured with a 24-gauge needle, and the contents were aspirated and filtered through a filter of $0.45 \mu \mathrm{m}$ pore size. NC and capacitated stallion sperm were incubated in a $10 \% \mathrm{v} / \mathrm{v}$ solution of FF in BWW medium and then processed for the assessment of the acrosome reaction.

\section{Analysis of membrane raft distribution}

The localisation of membrane raft marker, GM1 ganglioside, was visualised in stallion spermatozoa by staining with Alexa Fluor 555-labelled B subunit of cholera toxin B (CTB) as described previously for human spermatozoa (Nixon et al. 2011). For each treatment, 200 cells were classified into two fluorescent patterns (head and tail or head-only labelling).

\section{Heterologous equine sperm-bovine zona pellucida-binding assay}

\section{Oocyte recovery}

Post-mortem bovine ovaries were obtained from a local slaughterhouse and transported to the laboratory at $\sim 30{ }^{\circ} \mathrm{C}$ in pre-warmed Dulbecco's PBS (DPBS). Ovaries were washed with fresh DPBS, and then the contents of all the follicles were aspirated using a 20-gauge needle and $10 \mathrm{ml}$ syringe. Oocytes were allowed $15 \mathrm{~min}$ to settle to the bottom of pre-warmed glass tubes before being manually selected under a dissection microscope. Oocytes were then washed and placed into fresh DPBS containing $0.03 \%$ hyaluronidase. Cumulus cells were gently removed with a $135 \mu \mathrm{m}$ denuding pipette (Hunter Scientific, Essex, UK), and zona-intact oocytes were then transferred to a high-salt storage solution $(0.75 \mathrm{M}$ $\mathrm{MgCl}_{2}\left(\mathrm{H}_{2} \mathrm{O}\right)_{6}, 0.5 \mathrm{M}\left(\mathrm{NH}_{4}\right)_{2} \mathrm{SO}_{4}, 40 \mathrm{mM}$ HEPES buffer and $0.1 \mathrm{mg} / \mathrm{ml} \mathrm{PVA}$ ) and stored at $4{ }^{\circ} \mathrm{C}$ for up to 2 weeks.

\section{Gamete preparation and co-incubation}

In sterile tissue culture petri dishes, $100 \mu$ droplets of BWW medium were prepared under $\mathrm{H}_{2} \mathrm{O}$-saturated mineral oil. Salt-stored bovine oocytes were washed four times with DPBS using a denuding pipette, and four oocytes were placed into each BWW medium droplet and equilibrated at $37^{\circ} \mathrm{C}$ under $5 \% \mathrm{CO}_{2}$ for $1 \mathrm{~h}$. Sperm were capacitated in appropriate capacitating media for $4 \mathrm{~h}$, and a control population was prepared in NC BWW media. Approximately 20000 sperm cells were added to each group of four oocytes and gametes were co-incubated for $1 \mathrm{~h}$ at $37^{\circ} \mathrm{C}$ under $5 \% \mathrm{CO}_{2}$. Oocytes and attached sperm were then removed and washed five times with BWW medium by gentle aspiration to remove unbound sperm. Oocytes were then mounted on a glass slide in a small volume of BWW medium under a coverslip. The number of zona pellucida (ZP)-bound spermatozoa was recorded using phase-contrast microscopy.

\section{Acrosome assessment}

Following capacitation under different medium conditions, stallion spermatozoa were incubated for $30 \mathrm{~min}$ with $15 \mu \mathrm{m}$ progesterone, $0.5 \% \mathrm{v} / \mathrm{v}$ dimethylsulphoxide (DMSO) vehicle control, or $2.5 \mu \mathrm{m}$ calcium ionophore (A23187) to induce acrosomal exocytosis. Sperm were then incubated in pre-warmed hypo-osmotic swelling media $(0.07 \% \mathrm{w} / \mathrm{v}$ sodium citrate and $1.3 \% \mathrm{w} / \mathrm{v}$ fructose) for a further $30 \mathrm{~min}$ at $37^{\circ} \mathrm{C}$. Sperm preparations were then washed with PBS, aliquoted onto poly-L-lysine-coated slides and allowed to air-dry. The cells were then permeabilised in ice-cold methanol and subjected to immunocytochemistry with TRITC-labelled peanut agglutinin lectin (PNA, 1:200). The acrosomal status of stallion spermatozoa was assessed with a Zeiss LSM510 laser scanning confocal microscope by scoring the number of viable cells with intact acrosomes fluorescently labelled with PNA and the number of acrosome-reacted cells. Acrosome-reacted cells were identified by either the complete absence of PNA staining over the acrosomal region or the restriction of this labelling to the equatorial segment of the sperm head (Rathi et al. 2001).

\section{Statistical analysis}

Statistical significance was determined using ANOVA, TukeyKramer HSD and t-tests employing JMP software (version 9.0.0). $P<0.05$ was considered significant. Experiments were carried out on three pooled ejaculates from three stallions $(n=3)$ unless otherwise stated. All the data are expressed as means \pm S.E.M.

\section{Results}

\section{Experiment 1: a comparison of the capacitation status of stallion sperm transported in a non-capacitating medium and Kenney's milk-based semen extender}

To address the first aim of this study, a NC transport medium (NC BWW) was formulated based on a modified recipe of Biggers, Whitten and Whittingham medium in which bicarbonate was omitted. Before use, NC BWW medium was examined to ensure that it was capable of supporting levels of stallion sperm motility (Fig. 1A) and viability (Supplementary Figure 1, see section on supplementary data given at the end of this article) comparable to those supported by a commonly used equine semen extender comprising powdered skimmed milk, glucose, and antibiotics (Kenney's extender; Kenney et al. 1975) during the period of transport $\left(<1 \mathrm{~h}\right.$ at $\left.37^{\circ} \mathrm{C}\right)$ from the site of semen collection to our laboratory. Immediately after Percoll fractionation $(t=0)$, no significant difference $(P>0.05)$ was observed between the total mean motility of samples transported in Kenney's extender and that of samples transported in NC BWW medium (Fig. 1A). A similar trend was observed throughout the ensuing $4 \mathrm{~h}$ after transportation, though, as expected in the absence of a protein source, at later time points $(t=18$ and $32 \mathrm{~h}$, 
A

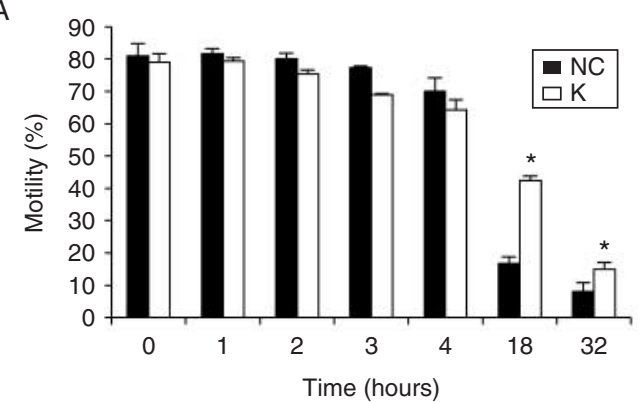

D
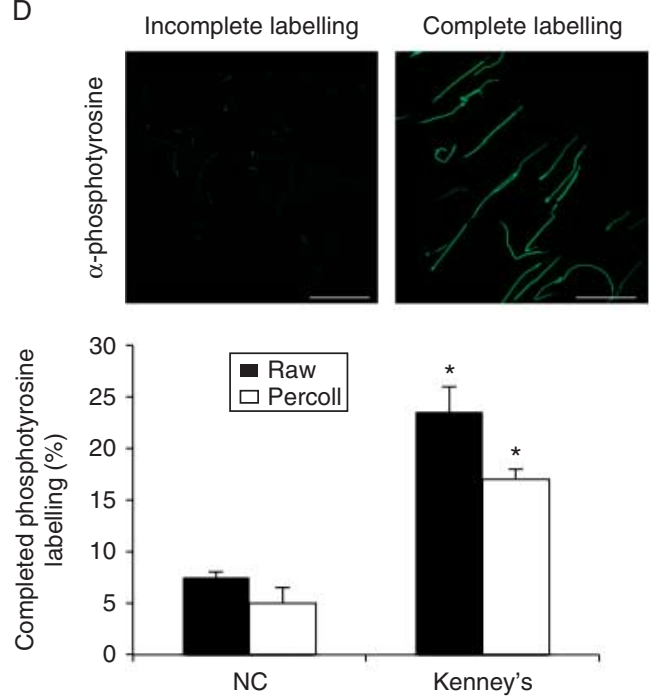

B

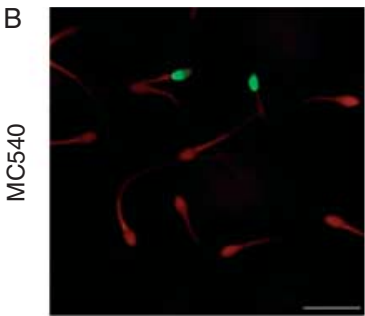

C

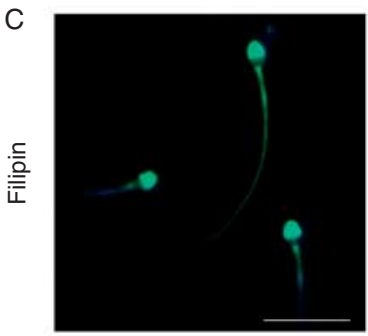

E

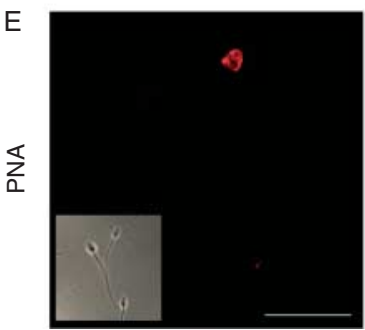

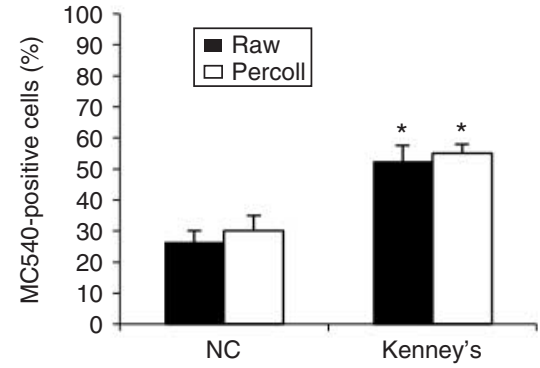
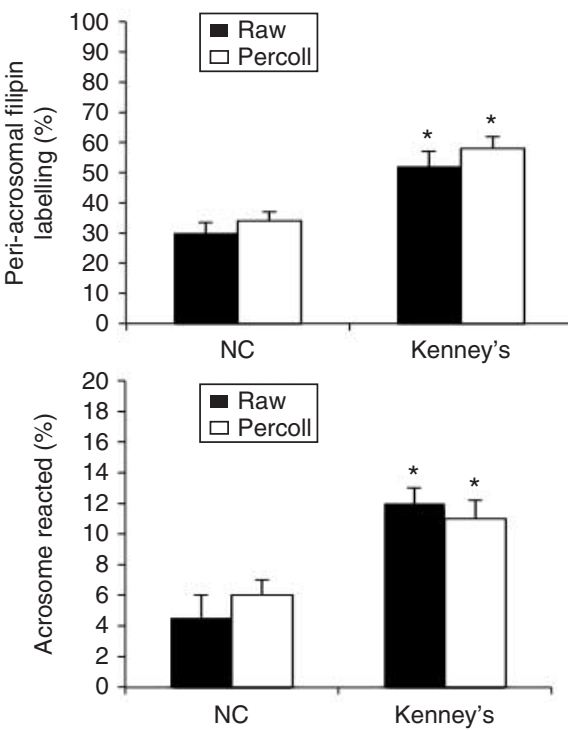

Figure 1 Comparative analysis of motility and capacitation-like changes in stallion spermatozoa transported in NC BWW medium or Kenney's semen extender. Immediately after collection, stallion semen was diluted 2:1 (v/v) in either NC BWW medium (NC) or Kenney's extender (K), before being transported to the laboratory for analysis within $1 \mathrm{~h}$ of ejaculation. (A) After Percoll fractionation (Percoll) or recovery from the unfractionated sperm pellet (raw), total motility was recorded using a HTM-IVOS CASA system immediately after removal of the extenders $(t=0)$ and at time points of up to $32 \mathrm{~h}$ thereafter. Simultaneously, live spermatozoa were stained with either SYTOX Green/MC540 or filipin, after which patterns of fluorescence were examined under a fluorescence microscope. (B) The percentage of MC540-positive spermatozoa in samples transported to the laboratory in NC BWW medium and Kenney's extender was recorded, and it is presented as means \pm s.E.M. $(n=3), * P \leq 0.02$. Scale bar $=20 \mu \mathrm{m}$. (C) The percentage of sperm displaying acrosomal labelling and minimal post-equatorial fluorescence was recorded as filipin positive, and it is presented as means \pm s.E.M. $(n=3),{ }^{*} P \leq 0.02$. Scale bar $=10 \mu \mathrm{m}$. (D) Populations of Percoll-enriched or unfractionated (raw) stallion spermatozoa were also fixed in $4 \%$ paraformaldehyde. These cells were then permeabilised with $0.2 \%$ Triton X-100 and stained with a FITC-conjugated antibody to phosphotyrosine (PT66). Phosphotyrosine labelling was observed in two distinct patterns: 'incomplete labelling' of the sperm flagella with fluorescence present over the mid-piece of the flagella and equatorial region of the sperm head and 'complete' labelling with fluorescence observed over the entire flagella. Representative images of phosphotyrosine expression were captured using a confocal microscope. The percentage of cells in each population displaying complete phosphotyrosine labelling of the flagella was recorded, $* P \leq 0.05$. Scale bar $=20 \mu \mathrm{m}$. (E) The percentage of cells exhibiting spontaneous acrosome loss was also recorded for spermatozoa transported in either non-capacitating BWW medium or Kenney's extender by assessment of TRITC-conjugated PNA labelling, $* P \leq 0.05$. The accompanying image displays representative images of acrosome-intact (red fluorescent labelling of the outer acrosomal membrane of the sperm head) and acrosome-reacted (no labelling) sperm cells. Scale bar $=15 \mu \mathrm{m}$.

incubated at $\left.37^{\circ} \mathrm{C}\right)$, a significantly greater $(P<0.05)$ percentage of motile spermatozoa were observed in samples transported in Kenney's extender (42 and 15\% respectively) than in those transported in NC BWW medium (16 and $8 \%$ respectively). The assessment of sperm viability over the same time course indicated that both NC BWW medium and Kenney's extender supported similar levels of cell viability (Supplementary Figure 1). Collectively, these data support the suitability of NC BWW medium for use as a short-term transport medium for stallion spermatozoa.
Experiments were then carried out to analyse the irreversible effects of these semen extenders on the stability of the stallion sperm membrane. To examine membrane fluidity, MC540 was employed. Populations of spermatozoa transported in Kenney's extender had a higher percentage of MC540-positive cells (55\%) compared with those of spermatozoa transported in NC BWW medium (30\%, $P<0.05$; Fig. 1B). As merocyanine is incorporated into sperm membranes that are in a state of lipid disorder, this result suggests that a greater proportion of sperm transported in Kenney's 
extender had undergone some degree of membrane phospholipid scrambling compared with those transported in NC BWW medium. To assess whether this result was influenced by a loss of cholesterol from the sperm membrane, the antibiotic filipin was used to monitor filipin-sterol complexes in stallion sperm.

Previous work carried out with this probe by Flesch et al. (2001) has verified that cholesterol is distributed over the entire head of non-capacitated boar spermatozoa. However, incubation of these cells in the presence of bicarbonate to induce capacitation resulted in a shift of filipin-cholesterol complexes to the peri-acrosomal region of the sperm head and a depletion of sterols from the equatorial and post-acrosomal regions of the sperm head (Flesch et al. 2001). In our study, both these filipincholesterol labelling patterns were identified in stallion sperm transported in NC BWW medium and Kenney's extender. Spermatozoa displayed either prominent postacrosomal labelling of the sperm head or an alternative labelling of the peri-acrosomal region with minimal fluorescence over the post-acrosomal domain (Fig. 1C). Consistent with the results obtained using merocyanine, a greater number of sperm transported in Kenney's extender showed redistribution of cholesterol to the periacrosomal region of the sperm head (Fig. 1C). Indeed, the proportion of sperm with cholesterol concentrated in the peri-acrosomal region of the sperm head in samples transported in NC BWW medium (34\%) and Kenney's extender (58\%) was virtually identical to the percentage of MC540-responsive sperm in samples transported in each of these transport media ( 30 vs $55 \%$ ).

Given that the events upstream of protein kinase A (PKA) stimulation and soluble adenylyl cyclase induction appear to have been influenced by semen extenders during transport, protein tyrosine phosphorylation, the key downstream consequence of activation of the CAMP/PKA pathway, was assessed in samples of the NC BWW medium- and Kenney's extender-transported sperm. 'Complete' phosphotyrosine labelling (Fig. 1D) of the sperm flagellum was observed in a significantly greater number of sperm transported in Kenney's extender $(17 \%)$ than in those transported in NC BWW medium (5\%) (Fig. 1D). Interestingly, the proportion of sperm displaying increases in phosphotyrosine expression was considerably lower than the number of sperm that appeared to have undergone a degree of membrane reorganisation, indicating that the changes observed after semen transport were unlikely to be a result of physiological capacitation. Finally, TRITClabelled PNA assessment of NC BWW medium- and Kenney's extender-transported spermatozoa to assess acrosome integrity revealed that up to $12 \%$ of viable sperm were acrosome damaged in the samples transported in Kenney's extender, double the number that were observed in samples transported in NC BWW medium (Fig. 1E).

\section{Experiment 2: assessment of the effect of $\mathrm{m} \beta \mathrm{cd}$ on the efficacy of stallion sperm capacitation in vitro}

To determine whether the macromolecule PVA or the putative sterol acceptor soybean hydrolysate (SB; Goldberg et al. 1982, Van Ee 2009) could yield time-dependent increases in tyrosine phosphorylation comparable to that observed with BSA, a FITC-conjugated antibody to phosphotyrosine ( $\alpha$-PT66) was used to evaluate the number of cells displaying complete phosphotyrosine labelling of the flagellum. This analysis was carried out over a time course of $18 \mathrm{~h}$ during which stallion sperm were incubated in capacitating media (Table 1) in a $5 \% \mathrm{CO}_{2}$-saturated environment at $37^{\circ} \mathrm{C}$. As shown in Fig. $2 \mathrm{~A},>70 \%$ of the total sperm population displayed complete flagellum labelling for phosphotyrosine after $4 \mathrm{~h}$ of capacitation in vitro, regardless of the macromolecular content of the media. These levels differed significantly from those achieved under NC conditions at time points between 3 and $6 \mathrm{~h}(P<0.01)$. Across all time points evaluated, media containing $1 \mathrm{mg} / \mathrm{ml}$ PVA sustained the highest level of phosphotyrosine expression with $77 \%$ of spermatozoa displaying complete flagellum labelling after $5 \mathrm{~h}$ of incubation under capacitating conditions.

To determine the optimal period of incubation required to elicit capacitation without compromising sperm viability, sperm motility was assessed using a HTM-IVOS computer-assisted sperm analysis (CASA) system (Hamilton Thorne Bioscience, Beverly, MA, USA). This study revealed that incubation in media containing either BSA or PVA supported equivalent levels of sperm motility over the entire time course examined (Fig. 2B). Although media containing $1.2 \mathrm{mg} / \mathrm{ml} \mathrm{SB}$ were also initially able to support levels of cell motility that were statistically similar to those supported by PVA- or BSA-based media, this level of support did not extend beyond $5 \mathrm{~h}$ of incubation. Given that high levels of tyrosine phosphorylation could be achieved after $4 \mathrm{~h}$ of incubation in capacitation media regardless of the macromolecule employed, and adequate sperm motility could still be maintained at this time point, an incubation time of $4 \mathrm{~h}$ was chosen for subsequent experiments. These experiments initially focused on establishing the quantitative increase in tyrosine phosphorylation in the presence of media containing BSA, PVA, or SB. They also served to evaluate the influence of pentoxifylline (ptx), a phosphodiesterase inhibitor, and dibutyryl cyclic AMP (dbcAMP), a membrane-permeable cAMP analogue, on the capacitation of stallion spermatozoa.

Immunoblotting data suggested that BSA was more effective in promoting stallion sperm protein tyrosine phosphorylation than either PVA or SB (Fig. 2C, D, and $\mathrm{E})$. In this regard, it was found that incubating stallion sperm in BWW medium with the addition of $25 \mathrm{mM}$ bicarbonate and $3 \mathrm{mg} / \mathrm{ml}$ BSA (Bic (BSA)) but in the absence of ptx and dbcAMP promoted a modest 
up-regulation of protein tyrosine phosphorylation after $4 \mathrm{~h}$ of incubation compared with the basal levels observed in sperm incubated in NC BWW medium. However, in the presence of $3 \mathrm{mM}$ ptx and $5 \mathrm{mM}$ dbcAMP (CAP (BSA)), a notable increase in the intensity of bands corresponding to a subset of proteins of $\sim 70-170 \mathrm{kDa}$ was detected (Fig. 2C). Immunoblotting analysis showed that an equivalent medium containing $1 \mathrm{mg} / \mathrm{ml}$ of PVA (CAP (PVA)) elicited a modest increase in protein tyrosine phosphorylation (Fig. 2D). Interestingly, phosphotyrosine levels observed in protein lysates extracted from sperm incubated in media containing SB were more comparable to those observed
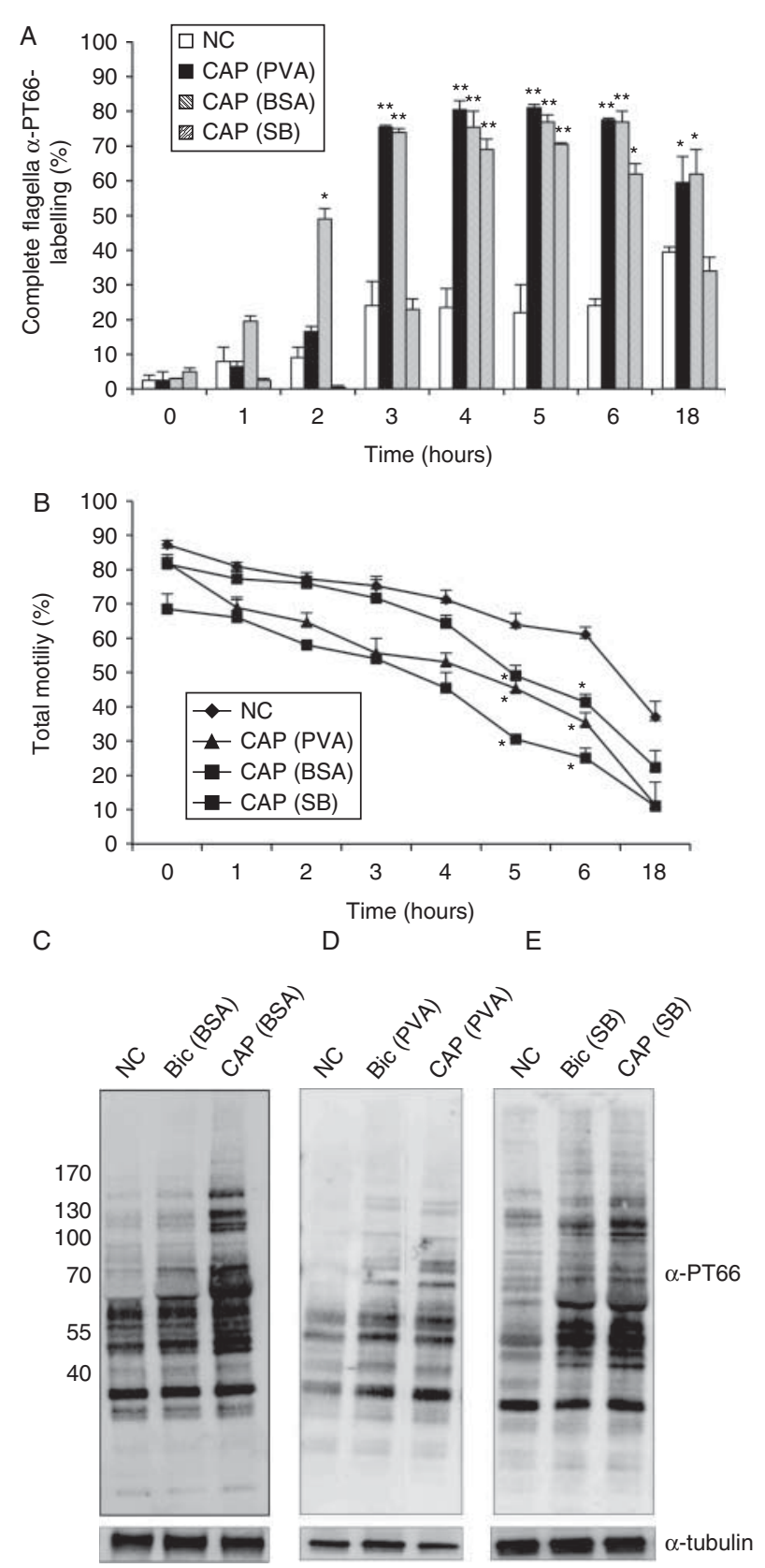

in lysates obtained from sperm incubated in media containing BSA (Fig. 2E).

Given this result, the potential efficacy of PVA, SB, and BSA was further assessed through their combination with the cyclic heptasaccharide $\mathrm{m} \beta \mathrm{cd}$ (Fig. 3). Although the addition of $0.5 \mathrm{mM} \mathrm{m \beta cd}$ to $\mathrm{NC}$ media did not dramatically alter the protein tyrosine phosphorylation profile of stallion spermatozoa, this analysis revealed an elevated level of phosphotyrosine (of proteins between $\sim 130$ and $170 \mathrm{kDa}$ ) in lysates extracted from sperm incubated in PVA-based media with $0.5 \mathrm{mM} \mathrm{m \beta cd}$ than in those prepared from sperm incubated in the absence of this cholesterol-withdrawing agent (Fig. 3A). A similar trend was also observed for spermatozoa incubated in $\mathrm{SB}$ media with and without $0.5 \mathrm{mM} \mathrm{m} \beta \mathrm{cd}$. In contrast to the results obtained for both SB- and PVA-supplemented media, the addition of $0.5 \mathrm{mM} \mathrm{m} \beta c d$ to sperm incubated in a BSA-rich environment did not appear to alter the

Figure 2 The influence of macromolecules on sperm protein tyrosine phosphorylation and motility during in vitro capacitation. Raw semen samples from three stallions were diluted in NC BWW medium $(2: 1)$, transported to the laboratory, and processed through Percoll centrifugation. (A) An equivalent number of pelleted spermatozoa were allocated to different treatment groups (NC BWW medium (NC); BWW medium supplemented with $1 \mathrm{mg} / \mathrm{ml}$ PVA, $3 \mathrm{mM}$ ptx, and $5 \mathrm{mM}$ dbcAMP (CAP (PVA)); BWW medium supplemented with $3 \mathrm{mg} / \mathrm{ml}$ BSA, $3 \mathrm{mM} \mathrm{ptx}$, and $5 \mathrm{mM}$ dbcAMP (CAP (BSA)); or BWW medium supplemented with $1.2 \mathrm{mg} / \mathrm{ml} \mathrm{SB}, 3 \mathrm{mM} \mathrm{ptx}$, and $5 \mathrm{mM}$ dbcAMP (CAP $(\mathrm{SB}))$. These cells were then incubated over an 18 -h period with aliquots removed and prepared for immunocytochemical labelling with FITCconjugated anti-phosphotyrosine at regular time points. The percentage of cells displaying complete labelling of the flagella was recorded, and it is presented as means \pm s.E.M. $(n=3), * P \leq 0.05$ and ${ }^{* *} P \leq 0.01$ for difference from the non-capacitated control. (B) Total motility was also recorded at each time interval using a HTM-IVOS CASA system utilising the manufacturer's settings for equine spermatozoa (Hamilton-Thorne Bioscience, version 12.3), and the data are presented as means \pm s.E.M. $(n=3),{ }^{*} P \leq 0.05$ for difference between the treatment groups.

(C, D, and E) At the 4-h time point, an aliquot of stallion spermatozoa from each treatment group was lysed and proteins were prepared for immunoblotting with a HRP-conjugated anti-phosphotyrosine antibody ( $\alpha$-PT66). Following development, the blots were stripped and re-probed with anti- $\alpha$-tubulin to ensure equivalent protein loading. This experiment was repeated three times, and representative immunoblots are shown. (C) Sperm were incubated in NC BWW medium devoid of bicarbonate and a macromolecule (NC); BWW medium supplemented with $3 \mathrm{mg} / \mathrm{ml}$ of BSA and $25 \mathrm{mM}$ bicarbonate (Bic (BSA)); or BWW medium supplemented with $3 \mathrm{mg} / \mathrm{ml}$ of BSA, $25 \mathrm{mM}$ bicarbonate, $3 \mathrm{mM}$ pentoxifylline, and $5 \mathrm{mM}$ dbcAMP (CAP (BSA)). (D) Sperm were incubated in NC BWW medium devoid of bicarbonate and a macromolecule (NC); BWW medium supplemented with $1 \mathrm{mg} / \mathrm{ml}$ of PVA and $25 \mathrm{mM}$ bicarbonate (Bic (PVA)); or BWW medium supplemented with $1 \mathrm{mg} / \mathrm{ml}$ of PVA, $25 \mathrm{mM}$ bicarbonate, $3 \mathrm{mM}$ pentoxifylline, and $5 \mathrm{mM}$ dbcAMP (CAP (PVA)). (E) Sperm were incubated in NC BWW medium devoid of bicarbonate and a macromolecule (NC); BWW medium supplemented with $1.2 \mathrm{mg} / \mathrm{ml}$ of SB and $25 \mathrm{mM}$ bicarbonate (Bic (SB)); or BWW medium supplemented with $1.2 \mathrm{mg} / \mathrm{ml}$ of $\mathrm{SB}, 25 \mathrm{mM}$ bicarbonate, $3 \mathrm{mM}$ pentoxifylline, and 5 mM dbcAMP (CAP (SB)). 
A

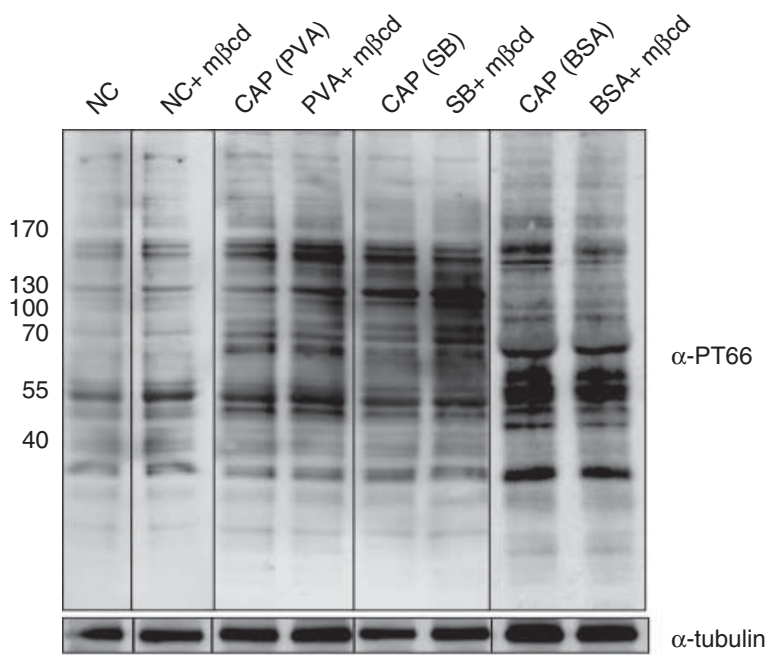

B

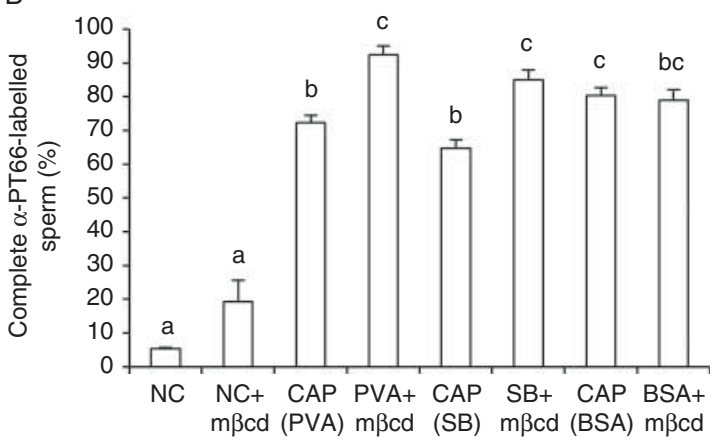

Figure 3 Assessment of the tyrosine phosphorylation status of sperm incubated in BSA-, SB-, and PVA-enriched BWW media supplemented with $\mathrm{m} \beta \mathrm{cd}$. BWW media supplemented with $3 \mathrm{mM}$ ptx, $5 \mathrm{mM}$ $\mathrm{dbcAMP}$, and $1 \mathrm{mg} / \mathrm{ml} \mathrm{PVA} ; 3 \mathrm{mg} / \mathrm{ml} \mathrm{BSA}$; or $1.2 \mathrm{mg} / \mathrm{ml} \mathrm{SB}$ were prepared in triplicate. $\mathrm{m} \beta \mathrm{cd}$ was then added at a concentration of $0.5 \mathrm{mM}$ to these media. Percoll-purified stallion spermatozoa were resuspended at a concentration of $10 \times 10^{6} \mathrm{cells} / \mathrm{ml}$ in each medium as well as in NC BWW medium (NC) as a negative control. The cell suspensions were incubated for $4 \mathrm{~h}$, after which the spermatozoa were either lysed with SDS extraction buffer for immunoblotting or fixed in $4 \%$ paraformaldehyde for immunocytochemistry. (A) Sperm lysates were prepared for immunoblotting with HRP-conjugated $\alpha$-PT66. Following development, the blots were stripped and re-probed for anti$\alpha$-tubulin to ensure equivalent protein loading. This experiment was repeated three times, and representative immunoblots are shown. (B) Immunocytochemistry was performed with FITC-conjugated $\alpha$-PT66, and the percentage of cells in each population displaying complete phosphotyrosine labelling of the flagella was recorded. Data are presented as means \pm S.E.M. $(n=3)$. ${ }^{a, b}, \mathrm{c}$ Mean values without a common superscript differ significantly, $P \leq 0.05$.

pattern of tyrosine phosphorylation compared with that observed for sperm incubated in BSA media devoid of the cholesterol-withdrawing agent. Importantly, these results were not an artefact of uneven loading of samples as verified through $\alpha$-tubulin (Fig. 3A).

These results were supported by our immunolabelling studies. Notably, the addition of this cholesterol-withdrawing agent promoted a significant increase in the number of spermatozoa displaying tyrosine phosphorylation in PVA- and SB-supplemented media (Fig. 3B). Interestingly, the addition of $\mathrm{m} \beta \mathrm{cd}$ to media containing BSA produced no pronounced additive effects on the level of tyrosine phosphorylation achieved in these spermatozoa ( 80 vs $79 \%$ respectively (Fig. $3 \mathrm{~B}$ )), and the addition of $\mathrm{m} \beta \mathrm{cd}$ to $\mathrm{NC}$ media resulted in a subtle increase in protein tyrosine phosphorylation that was not statistically significant (5 vs $19 \%$ respectively).

Given that the inclusion of $\mathrm{m} \beta \mathrm{cd}$ promoted an increase in protein tyrosine phosphorylation in media devoid of the traditional cholesterol acceptor BSA, both PVA- and SB-enriched capacitation media prepared with and without $\mathrm{m} \beta \mathrm{cd}$ were analysed for their effects on membrane raft distribution after in vitro capacitation. For this purpose, spermatozoa were labelled with CTB to study the distribution of GM1 gangliosides, a key component of the raft environment (Nixon et al. 2010, 2011). The pattern of CTB labelling typically observed under NC conditions was defined by uniform fluorescence over the entire surface of the sperm (Fig. 4A). However, incubation in the sperm capacitation media formulated for these studies elicited a marked redistribution of CTB staining to one that was restricted to the periacrosomal region of the sperm head. This result shares a striking similarity to previous observations of the GM1 ganglioside localisation reported in boar, human, and mouse sperm following incubation under capacitating conditions (Shadan et al. 2004, Nixon et al. 2010, 2011).

Quantification of these images revealed that the addition of $\mathrm{m} \beta \mathrm{cd}$ to PVA- and BSA-based media resulted in increases in the number of sperm displaying a capacitation-associated redistribution of GM1 gangliosides to the peri-acrosomal region of the sperm head (74 vs $87 \%$ ) or ( 66 vs $85 \%$ ) respectively. The addition of $\mathrm{m} \beta \mathrm{cd}$ also led to a significant increase in the number of sperm displaying restricted peri-acrosomal labelling of the sperm head after capacitation in media containing SB (52 vs $74 \%$ ). Moreover, the addition of $\mathrm{m} \beta \mathrm{cd}$ to $\mathrm{NC}$ media also resulted in a significant increase in the number of sperm presenting this positive labelling pattern of membrane raft redistribution (8 vs $34 \%$ respectively).

Based on phosphotyrosine expression and membrane raft localisation, it was concluded that the addition of $\mathrm{m} \beta \mathrm{cd}$ to BWW medium containing PVA, BSA, or SB in addition to the pharmacological agents, ptx/dbcAMP, promoted the highest levels of capacitation in sperm in all the media assessed. Therefore, these experimental conditions were selected for the assessment of sperm function using a heterologous sperm-ZP binding assay. Though no significant difference in sperm motility was observed in SB-, PVA-, and BSA-supplemented media containing $\mathrm{m} \beta c \mathrm{~d}$ and $\mathrm{pt} \times \mathrm{dbcAMP}$, a dramatic difference in ZP-binding competence was identified (Fig. 4C). As anticipated, stallion spermatozoa incubated in NC BWW medium demonstrated very limited affinity for 

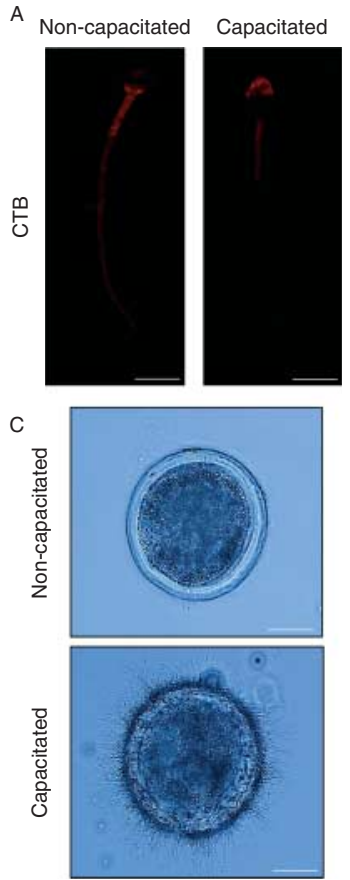
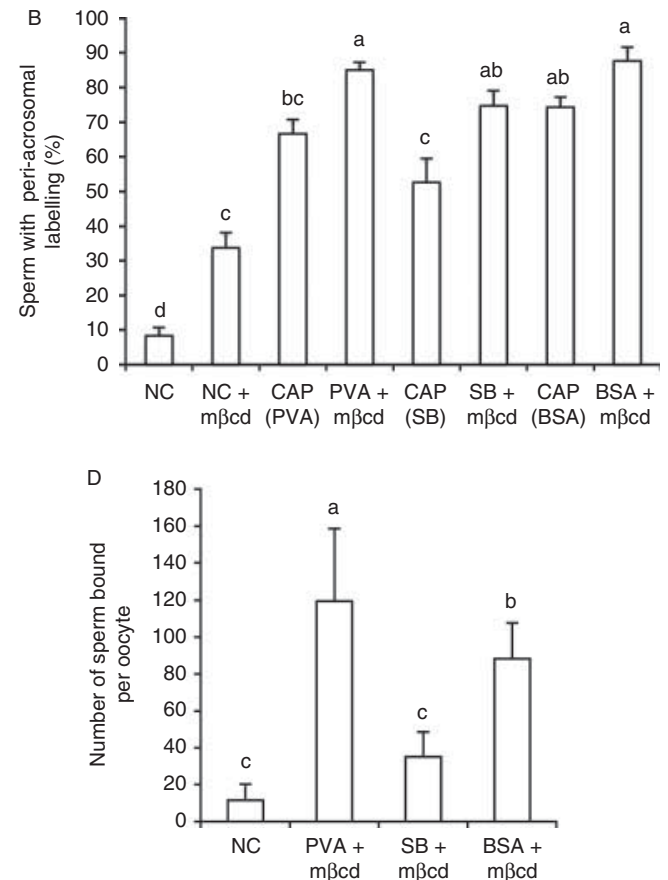

Figure 4 Analysis of lipid raft distribution and ZP-binding ability of stallion spermatozoa incubated under capacitating conditions. (A) Representative CTB labelling patterns exhibited by cells incubated under non-capacitating conditions and capacitating conditions. (B) The proportion of spermatozoa displaying the restricted labelling of GM1 gangliosides characteristic of capacitated cells in response to incubation in BWW media supplemented with $3 \mathrm{mM}$ ptx, $5 \mathrm{mM}$ dbcAMP, and a macromolecule (PVA, BSA, or SB), prepared with and without the addition of m $\beta c d$, was recorded. Mean values without a common superscript $(a, b, c, d)$ differ significantly $(P \leq 0.01)$. Scale bar $=10 \mu \mathrm{m}$. (C and D) Stallion spermatozoa were incubated in NC BWW or BWW media optimised to promote capacitation (BWW medium incorporating $3 \mathrm{mM} \mathrm{ptx}, 5 \mathrm{mM} \mathrm{dbcAMP,} \mathrm{m \beta cd,} \mathrm{and} \mathrm{PVA,}$ $\mathrm{BSA}$, or SB) for $4 \mathrm{~h}$. The spermatozoa were then co-incubated with ZP-intact, salt-stored bovine oocytes for $1 \mathrm{~h}$. After five washes to remove unbound sperm, oocytes were mounted on glass slides, and bound sperm were counted using phase-contrast microscopy. (C) Representative images of zona binding observed for non-capacitated spermatozoa and those capacitated in PVA $+\mathrm{m} \beta c d$. Scale bar $=50 \mu \mathrm{m}$. (D) The average number of sperm bound for each treatment was recorded. This experiment was performed in triplicate with a minimum of four oocytes assessed per treatment group for each replicate. ${ }^{\mathrm{a}, \mathrm{b}, \mathrm{c}}$ Mean values without a common superscript differ significantly $(P \leq 0.001)$.

bovine ZP, with an average of 11.6 sperm bound/egg. Conversely, sperm incubated in media containing a combination of ptx/dbcAMP, PVA and m $\beta c d$ exhibited a high affinity for bovine ZPs with an average of 119 sperm bound per oocyte (Fig. 4D).

Given that capacitation media containing BSA supported membrane raft redistribution in a greater proportion of cells and promoted tyrosine phosphorylation of an additional subset of proteins compared with PVA-supplemented media, it was surprising that opposing results were observed in terms of their ability to support sperm binding to bovine ZP (88.3 vs 119.4 sperm/egg respectively). This dichotomy may be attributed to a slightly higher frequency of sperm-sperm agglutination observed in the presence of serum albumin (Supplementary Figure 1), or alternatively protein tyrosine phosphorylation in this species may not be an adequate predictor of fertilising capacity. Despite this, BSA-rich media did promote greater ZP-binding competence than media containing both a combination of $\mathrm{SB}$ and $\mathrm{m} \beta \mathrm{cd}$ (CAP (SB)), where an average of 35 sperm bound to oocytes. This result did not significantly differ from non-capacitated cells $(P>0.05)$.
In addition, we sought to evaluate which medium best supported high levels of acrosomal exocytosis. This was accomplished through the exposure of capacitated stallion spermatozoa to progesterone and the calcium ionophore A23187, before using TRITClabelled PNA to assess the acrosomal status of the cells (Fig. 5A). Since equine FF has been shown to induce acrosomal exocytosis in stallion sperm (Rodriguez et al. 2001), as a positive control, spermatozoa were capacitated in BWW medium supplemented with ptx/dbcAMP for $4 \mathrm{~h}$ and then pre-incubated with $10 \%$ equine $\mathrm{FF}$ for $30 \mathrm{~min}$ before fixation in $4 \%$ paraformaldehyde.

These experiments revealed that media containing $\mathrm{m} \beta \mathrm{cd}$ consistently supported the highest rates of acrosomal exocytosis in stallion sperm, and these levels proved to be statistically similar to those induced through a 30-min incubation in equine FF (Fig. 5B). In all cases, incubation with the calcium ionophore A23187 induced the highest levels of acrosomal exocytosis (Fig. 5B), and no statistically significant difference was discernible between the macromolecules: BSA, PVA, and SB. 

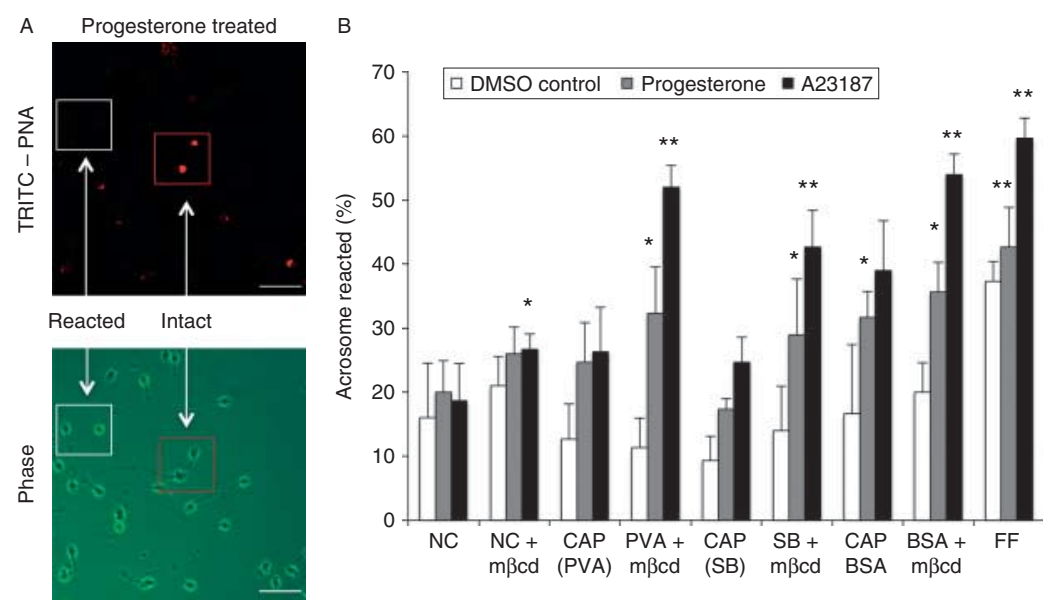

Figure 5 Assessment of the ability of stallion spermatozoa to acrosome react following capacitation. Stallion spermatozoa incubated in capacitating media ( $3 \mathrm{mM}$ ptx and $5 \mathrm{mM}$ dbcAMP) containing PVA, BSA, or SB with and without the addition of $\mathrm{m} \beta c d$ were induced to acrosome react with calcium ionophore A23187 or, in a parallel experiment, with progesterone P4. Following treatment, spermatozoa were incubated in hypo-osmotic swelling medium to distinguish live cells and then assessed for acrosomal status using TRITC-conjugated PNA. A control treatment in which sperm were incubated in FF was also carried out. (A) Representative images of acrosome-intact (PNA-labelled) and acrosome-reacted (non-labelled) stallion spermatozoa. Scale bar $=20 \mu \mathrm{m}$. (B) Assessment of acrosomal status was conducted for 100 viable (curled tails) spermatozoa in each treatment group by monitoring TRITC-PNA labelling under a fluorescence microscope. *Mean values differed significantly from the NC BWW medium (NC) control and from the DMSO control $(P \leq 0.05),{ }^{* * P} \leq 0.01$.

\section{Discussion}

\section{Experiment 1: premature 'capacitation-like changes' occur at elevated levels during semen transport in Kenney's extender compared with transport in NC BWW medium}

Existing research into the effects of semen extenders on equine sperm function has focused largely on the maintenance of sperm viability and motility during transport and storage (Brinsko et al. 2000, LeFrapper et al. 2010). Interestingly, the findings described in the present study suggest that adequate motility and viability after transport do not necessarily denote membrane stability and fertilising competence. The impact of an industry-standard milk-based semen extender on the maintenance of membrane stability was investigated through the examination of plasma membrane destabilisation and cholesterol depletion, two events frequently correlated with the onset of capacitation (Flesch et al. 2001), as well as sperm protein tyrosine phosphorylation and acrosome integrity. The results secured in this study demonstrated that short-term transport of stallion sperm in Kenney's extender permits greater levels of membrane fluidity and cholesterol redistribution compared with transport of sperm in a skimmed milk-free alternative transport medium. It is thus possible that Kenney's extender could render some cells more susceptible to a loss of membrane integrity, explaining the heightened levels of spontaneous acrosome loss that we observed immediately after transport in this study. Although it is not suggested that sperm in contact with Kenney's extender experience physiological capacitation, the presence of a number of cells displaying tyrosine phosphorylation of flagellar proteins suggests that a restricted population of stallion spermatozoa undergo capacitation-like changes that could reduce their longevity. A similar phenomenon has been found in other domestic animals such as the boar (Bailey \& Buhr 1994, Bailey et al. 2000). This could have particular implications with regard to the use of sperm stored in milk-based extenders for artificial insemination, where long-term sperm survival is crucial for successful fertilisation (Bailey et al. 2000), and for gamete intrafallopian transfer, where sperm are deposited directly into the oviduct and the components of semen extenders may be present during gamete interaction (Coutinho da Silva et al. 2012).

Although the mechanisms of sperm activation in the presence of milk proteins are poorly understood, it has recently been shown that incubation of stallion sperm in a skimmed milk-based extender (EZM) based on the composition of Kenney's extender (Kenney et al. 1975) promotes a fourfold increase in the number of cells capable of binding to either bovine or equine ZPs (Coutinho da Silva et al. 2012). Previously, these authors have demonstrated that the addition of milk proteins, casein, native phosphocaseinate, and caseinoglycopeptide, enhances the binding of stallion sperm to bovine and equine ZP in a dose-dependent manner (Coutinho da Silva et al. 2005). Interestingly, casein phosphopeptides have also been reported to be positively associated with the fertilisation of pig oocytes. In this regard, Nagai et al. (1988) observed a significant increase in ZP penetration rates when boar sperm were 
incubated in a medium containing casein phosphopeptides than when incubated in a medium without these supplements (100 vs $46 \%$ ). It is also worth noting that an increase in intracellular calcium concentrations was observed in stallion sperm following incubation in the presence of casein phosphopeptides, and a subsequent increase in the number of sperm able to undergo an induced acrosome reaction has been documented, suggesting that sperm capacitation may occur in the presence of milk proteins (Pommer et al. 2003).

Therefore, it is possible that casein and/or calcium present in the skimmed milk component of Kenney's extender contributed to the capacitation-like changes identified in our study. However, it should also be noted that several studies have implicated casein micelles as the active components involved in the protection of sperm from milk products. In the bull, for instance, it has been proposed that the casein micelles found in skimmed milk extenders are able to exert a cryoprotectant effect by virtue of their ability to sequester a family of seminal plasma lipid-binding proteins (bovine seminal plasma proteins (BSPs); Bergeron et al. 2007). This sequestration is, in turn, thought to counteract lipid loss during storage by preventing the BSPs from acting as a sink for phospholipid and cholesterol efflux from the plasma membrane (Bergeron et al. 2007). While it remains to be examined directly, our study strongly suggests an opposing role for the components of skimmed milk during stallion semen transport. However, if this hypothesis stands true, it may in part be attributed to an issue of dilution in that the quantity of skimmed milk in Kenney's extender used for these studies was not sufficient to bind a substantial quantity of BSP homologues and thus protect stallion sperm from lipid and cholesterol loss. While we were able to negate some of these issues through the use of NC BWW media, unusually high levels of membrane fluidity and cholesterol redistribution were also detected in populations of sperm transported in $\mathrm{NC}$ media regardless of the use of Percoll fractionation (Fig. 1). Although this is unlikely to be due to the composition of the media used, the use of centrifugation to remove the extender may have been sufficient to induce sperm membrane destabilisation. Indeed, stallion spermatozoa may be highly sensitive to the mechanical insults of handling and storage (Leahy \& Gadella 2011). Additionally, the cholesterol concentration of the stallion sperm plasma membrane is already quite low in comparison with that present in sperm of other species (Parks \& Lynch 1992, Cross 1998). As it is unlikely that NC BWW medium is able to provide the components necessary to sustain sperm motility and viability during long-term storage, investigations into novel semen extenders for the transport and storage of semen are thus required to circumvent the potential issues associated with the use of milk-based extenders in equids.

\section{Experiment 2: $\boldsymbol{m} \beta c d$ can enhance stallion sperm capacitation in vitro, as defined by protein tyrosine phosphorylation and the acquisition of ZP-binding potential}

In terms of addressing the second aim of this study, we were able to demonstrate that within a 4-h time frame, modified BWW media formulated to include bicarbonate and a macromolecule alone were sufficient to induce levels of tyrosine phosphorylation that superseded those observed under NC conditions (Fig. 2). However, the addition of $3 \mathrm{mM}$ ptx and $5 \mathrm{mM}$ dbcAMP was required to ensure that a majority of cells underwent the post-translational changes associated with capacitation. This may reflect the fact that in our study, spermatozoa were incubated in an atmosphere of $5 \% \mathrm{CO}_{2}$ in air. In view of recent work carried out by González-Fernández et al. (2012), it might be beneficial to extend these studies to assess the effects of our media on spermatozoa incubated in an air environment (González-Fernández et al. 2012). Nevertheless, our study did reveal that the addition of $\mathrm{m} \beta \mathrm{cd}$ might circumvent the need for traditional sterol acceptors derived from animal sources in in vitro capacitation media. Indeed, this reagent dramatically improved the efficacy of both PVA- and SB-based media in promoting tyrosine phosphorylation in stallion spermatozoa (Fig. 3).

In addition to tyrosine phosphorylation, we also focused our analysis on capacitation-associated surface remodelling events. Such events are critically important in preparing spermatozoa for fertilisation, particularly as the balance of evidence indicates that these cells are transcriptionally inactive (Yanagimachi 1994). In recent years, this process has been shown to be augmented by specialised microdomains known as membrane rafts. Upon capacitation, and the resultant cholesterol efflux, membrane rafts undergo a dynamic reorganisation from a uniform pattern of distribution to one that is confined to the apical ridge of the sperm head, the region that mediates zona recognition and binding (van Gestel et al. 2005a). Furthermore, among the key proteins identified within these microdomains are a subset of putative zona receptor molecules (Asano et al. 2009, 2010, Nixon et al. 2009, 2011). In the present study, incubation of sperm in the presence of $\mathrm{m} \beta \mathrm{cd}$ in combination with PVAand SB-based BWW media resulted in a significant increase in the number of sperm displaying membrane raft aggregation within the peri-acrosomal region of the sperm head (Fig. 4B). Additionally, these data were supported by our analysis of membrane fluidity using MC540 (Supplementary Figure $2 \mathrm{~A}$, see section on supplementary data given at the end of this article) and cholesterol depletion monitored using filipin (Supplementary Figure 2B). These analyses revealed a significant increase in membrane destabilisation events in treatment groups capacitated in the presence of $\mathrm{m} \beta c \mathrm{~cd}$ and either PVA or SB as well as when $\mathrm{m} \beta \mathrm{cd}$ was added to sperm incubated under NC conditions.

Since the capacitation-induced aggregation of membrane rafts is thought to be involved in the generation of 
sperm ZP-binding capability (Boerke et al. 2008), it was predicted that the inclusion of $\mathrm{m} \beta \mathrm{cd}$ in capacitating media would be advantageous for the promotion of ZP-binding ability in stallion spermatozoa.

This hypothesis was tested through the co-incubation of stallion sperm, capacitated in BWW medium supplemented with $\mathrm{m} \beta \mathrm{cd}$ and PVA, BSA or SB, with heterologous bovine zona-intact oocytes (Fig. 4D). This assay has recently been developed to address difficulties associated with the acquisition of sufficient horse oocytes and, importantly, has been used to assess stallion sperm capacitation status (Clulow et al. 2010, Coutinho da Silva et al. 2012). The use of this assay in our study demonstrated that media containing PVA and $\mathrm{m} \beta \mathrm{cd}$ supported the highest levels of ZP binding with an average of 119.4 sperm bound to the ZP of each bovine oocyte, a result that significantly exceeded the number of sperm bound after incubation in NC conditions (11.6 cells/oocyte). The gamete co-incubation method used in these studies was adapted from that established by Clulow et al. (2010) in studies of fresh and frozen, sex-sorted and non-sorted stallion spermatozoa. These authors demonstrated that after incubation in TALP and co-incubation with heterologous bovine oocytes, an average of fewer than 30 sperm were bound to each oocyte (Clulow et al. 2010). Similar results were obtained through binding assays incorporating equine sperm and bovine and equine oocytes, with averages of 29 and 36 sperm/egg being obtained respectively (Coutinho da Silva et al. 2012). In comparison, the number of sperm bound to oocytes after incubation in PVA/m $\beta c d$ (119.4 sperm/egg) and $\mathrm{BSA} / \mathrm{m} \beta \mathrm{cd}$ (88.3 sperm/egg) greatly exceeded those observed in previous studies. Despite showing promise in its ability to support protein tyrosine phosphorylation (Fig. 3) and high levels of agonist-induced acrosomal exocytosis (Fig. 5), the medium containing SB failed to support sperm-ZP interaction in vitro. Although there was no significant difference in the ability of each medium to support sperm motility (Fig. 2), capacitation in SB-based media resulted in the greatest reduction in motility at $4 \mathrm{~h}$ when compared with the non-capacitated control. Given this, it is possible that subtle differences in motility and patterns of hyperactivation may have affected the ability of these cells to bind tightly to the ZP.

Although media containing $\mathrm{m} \beta \mathrm{cd}$ promoted high levels of heterologous ZP interaction, a recent study of murine and porcine sperm capacitation has suggested that the artificial depletion of sterols mediated by this agent may result in low IVF rayes (Boerke et al. 2013). Such results purportedly stem from the dual action of this reagent in circumventing the bicarbonate-induced reactive oxygen species (ROS) oxysterol signalling pathway that leads to the removal of sperm surface sterols, in addition to its ability to induce oocyte degeneration in these species (Boerke et al. 2013). While the effect of $\mathrm{m} \beta \mathrm{cd}$ on equine IVF rates and equine oocyte quality is yet to be examined, the very low concentration encountered by oocytes in our study is likely to limit any detrimental influence of this reagent. Additionally, in contrast to the findings reported for pig spermatozoa (van Gestel et al. 2005b), we were able to demonstrate that as little as $0.5 \mathrm{mM} \mathrm{m} \beta \mathrm{cd}$ was able to enhance the redistribution and aggregation of membrane raft components (Fig. 4) in addition to an up-regulation of protein tyrosine phosphorylation (Fig. 3). These results may, in part, be attributed to the synergistic effects resulting from its combination with PVA or SB macromolecules. However, we cannot discount the possibility that this reagent also elicits species-specific effects.

While PVA-based BWW medium was able to support the highest levels of ZP-binding ability, one distinct difference between this medium and that supplemented with serum albumin was the greater number of agglutinated sperm in the latter treatment. This increase in agglutination is likely to have contributed to the reduced ZP-binding efficacy of the BSA and thus appears to be a negative attribute of this macromolecule. However, similarly high levels of agglutination were observed in populations of spermatozoa incubated in FF, thus implying that this mechanism may be of some physiological relevance. In studies carried out with boar spermatozoa, it has been demonstrated that the adenylyl cyclase-cAMP-PKA signalling cascade, which facilitates capacitation, may also lead to an increased propensity for head-to-head agglutination (Harayama et al. 2000). In this species, it is thought that the spermatozoa lose an anti-agglutinin molecule from their surface due to changes in the plasma membrane induced by a combination of serum albumin (Harayama et al. 1999), calcium chloride, and bicarbonate within the capacitation media (Harayama et al. 1998).

In conclusion, the results reported herein support the concept that cholesterol removal from the sperm plasma membrane is essential for capacitation, as defined by the coalescence of lipid rafts in the periacrosomal region of the sperm head, heterologous binding of stallion spermatozoa to ZP-intact bovine oocytes, and an inducible acrosome reaction. In numerous studies, it has been demonstrated that cholesterol depletion appears to be a rate-limiting step in capacitation and is vital for the activation of tyrosine kinases (Visconti et al. 1999, Flesch et al. 2001, Signorelli et al. 2012). Accordingly, these studies also highlight the positive correlation between cholesterol removal and protein tyrosine phosphorylation in stallion spermatozoa. Moreover, capacitation media containing PVA, ptx, and dbcAMP produced high levels of ZP binding when combined with $\mathrm{m} \beta \mathrm{cd}$ and may therefore hold promise as commercially applicable media that contain no animal-derived material for the in vitro capacitation of stallion spermatozoa. In addition, our study indicates that premature capacitation is not effectively attenuated in the presence of a milk-based commercially available semen extender, suggesting 
that a re-evaluation of diluents used to prevent the deleterious effects of seminal plasma is required.

\section{Supplementary data}

This is linked to the online version of the paper at http://dx.doi. org/10.1530/REP-13-0393.

\section{Declaration of interest}

The authors declare that there is no conflict of interest that could be perceived as prejudicing the impartiality of the research reported.

\section{Funding}

The authors gratefully acknowledge funding provided to R J Aitken by an Australian Research Council (ARC) Linkage Project Grant entitled Enhancing the efficiency of equine reproduction: novel approaches relevant to the Thoroughbred and Standardbred breeding industries. ARC Reference No: LP120100219. E G Bromfield is the recipient of an Australian Postgraduate Award PhD scholarship.

\section{References}

Aitken RJ, Ryan AL, Curry BJ \& Baker MA 2003 Multiple forms of redox activity in populations of human spermatozoa. Molecular Human Reproduction 9 645-661. (doi:10.1093/molehr/gag086)

Aitken RJ, Gibb Z, Mitchell LA, Lambourne SR, Connaughton HS \& De Iuliis GN 2012 Sperm motility is lost in vitro as a consequence of mitochondrial free radical production and the generation of electrophilic aldehydes but can be significantly rescued by the presence of nucleophilic thiols. Biology of Reproduction 87 110. (doi:10.1095/biolreprod.112. 102020)

Alm H, Torner H, Blottner S, Nurnberg G \& Kanitz W 2001 Effect of sperm cryopreservation and treatment with calcium ionophore or heparin on in vitro fertilization of horse oocytes. Theriogenology 56 817-829. (doi:10.1016/S0093-691X(01)00610-0)

Alvarez JG \& Storey BT 1983 Taurine, hypotaurine, epinephrine and albumin inhibit lipid peroxidation in rabbit spermatozoa and protect against loss of motility. Biology of Reproduction 29 548-555. (doi:10.1095/biolreprod29.3.548)

Asano A, Selvaraj V, Buttke DE, Nelson JL, Green KM, Evans JE \& Travis AJ 2009 Biochemical characterization of membrane fractions in murine sperm: identification of three distinct sub-types of membrane rafts. Journal of Cellular Physiology 218 537-548. (doi:10.1002/jcp.21623)

Asano A, Nelson JL, Zhang S \& Travis AJ 2010 Characterization of the proteomes associating with three distinct membrane raft sub-types in murine sperm. Proteomics 10 3494-3505. (doi:10.1002/pmic.201000002)

Bailey JL \& Buhr MM 1994 The impact of cryopreservation on $\mathrm{Ca}^{2+}$ regulation by bovine spermatozoa. Canadian Journal of Animal Science 74 53-58. (doi:10.4141/cjas94-008)

Bailey JL, Bilodeau J \& Cormier N 2000 Semen cryopreservation in domestic animals: a damaging and capacitating phenomenon. Journal of Andrology 21 1-7.

Bergeron A, Brindle Y, Blondin P \& Manjunath P 2007 Milk caseins decrease the binding of the major bovine seminal plasma proteins to sperm and prevent lipid loss from the sperm membrane during sperm storage. Biology of Reproduction 77 120-126. (doi:10.1095/biolreprod. 106.058248)

Bezard J 1992 In vitro fertilisation in the mare. In: Proceedings of the International Scientific Conference on Bioethics in Horse Reproduction 12. Crakow, Poland.
Biggers JD, Whitten WK \& Whittingham DG 1971 The culture of mouse embryos in vitro, San Francisco, USA: Freeman.

Blue BJ, McKinnon AO, Squires EL, Seidel GEj \& Muscari KT 1989 Capacitation of stallion spermatozoa and fertilization of equine oocytes in vitro. Equine Veterinary Journal 8 111-116.

Boerke A, Tsai PS, Garcia-Gil N, Brewis IA \& Gadella BM 2008 Capacitation-dependent reorganization of microdomains in the apical sperm head plasma membrane: functional relationship with zona binding and the zona-induced acrosome reaction. Theriogenology $\mathbf{7 0}$ 1188-1196. (doi:10.1016/j.theriogenology.2008.06.021)

Boerke A, Brouwers JF, Olkkonen VM, van de Lest CHA, Sostaric E, Schoevers EJ, Helms JB \& Gadella BM 2013 Involvement of bicarbonateinduced radical signaling in oxysterol formation and sterol depletion of capacitating mammalian sperm during in vitro fertilization. Biology of Reproduction 88 21. (doi:10.1095/biolreprod.112.101253)

Brackett BG, Bousquet D, Boice ML, Donawick WJ, Evans JF \& Dressel MA 1982 Normal development following in vitro fertilization in the cow. Biology of Reproduction 27 147-158. (doi:10.1095/biolreprod27.1.147)

Brinsko SP, Rowan KR, Varner DD \& Blanchard TL 2000 Effects of transport container and ambient storage temperature on motion characteristics of equine spermatozoa. Theriogenology 53 1641-1655. (doi:10.1016/ S0093-691X(00)00304-6)

Chamberland A, Fournier V, Tardif S, Sirand MA, Sullivan R \& Bailey JL 2001 The effect of heparin on motility parameters and protein phosphorylation during bovine sperm capacitation. Theriogenology 55 823-835. (doi:10.1016/S0093-691X(01)00446-0)

Choi YH, Landim-Alvarenga FC, Seidel GE \& Squires EL 2003 Effect of capacitation of stallion sperm with polyvinylalcohol or bovine serum albumin on penetration of bovine zona-free or partially zona-removed equine oocytes. Journal of Animal Science 81 2080-2087.

Christensen P, Whitfield CH \& Parkinson TJ 1996 In vitro induction of acrosome reactions in stallion spermatozoa by heparin and A23187. Theriogenology 45 1201-1210. (doi:10.1016/0093-691X(96)00075-1)

Clulow JR, Evans G, Maxwell WM \& Morris LH 2010 Evaluation of the function of fresh and frozen-thawed sex-sorted and non-sorted stallion spermatozoa using a heterologous oocyte binding assay. Reproduction, Fertility, and Development 22 710-717. (doi:10.1071/RD09033)

Coutinho da Silva MA, Seidel GE Jr, Squires EL \& Carnevale EM 2005 Casein, native phosphocaseinate and caseinoglycopeptide enhance binding of equine sperm to bovine zonae pellucidae. Newmarket, Suffolk: R \& W Communications.

Coutinho da Silva MA, Seidel GE Jr, Squires EL, Graham JK \& Carnevale EM 2012 Effects of components of semen extenders on the binding of stallion spermatozoa to bovine or equine zonae pellucidae. Reproduction 143 577-585. (doi:10.1530/REP-11-0099)

Cross NL 1998 Role of cholesterol in sperm capacitation. Biology of Reproduction 59 7-11. (doi:10.1095/biolreprod59.1.7)

Dell' Aquila ME, Cho YS, Minoia P, Traina V, Fusco S, Lacalandra GM \& Maritato F 1996 Intracytoplasmic sperm injection (ICSI) versus conventional IVF on abattoir-derived and in-vitro matured equine oocytes. Theriogenology 47 1139-1156. (doi:10.1016/S0093-691X(97)00095-2)

van Ee JH 2009 Soy constituents: modes of action in low-density lipoprotein management. Nutrition Reviews 67 222-234. (doi:10.1111/j.17534887.2009.00192.x)

Ellington JE, Ball BA, Blue BJ \& Wilker CE 1993 Capacitation-like membrane changes and prolonged viability in vitro of equine spermatozoa cultured with uterine tube epithelial cells. American Journal of Veterinary Research $\mathbf{5 4}$ 1505-1510.

Flesch FM, Brouwers JF, Nievelstein PF, Verkleij AJ, van golde LM, Colenbrander B \& Gadella BM 2001 Bicarbonate stimulated phospholipid scrambling induces cholesterol redistribution and enables cholesterol depletion in the sperm plasma membrane. Journal of Cell Science 114 3543-3555.

Galantino-Homer HL, Visconti PE \& Kopf GS 1997 Regulation of protein tyrosine phosphorylation during bovine sperm capacitation by a cyclic adenosine $3^{\prime} 5^{\prime}$-monophosphate-dependent pathway. Biology of Reproduction 56 707-719. (doi:10.1095/biolreprod56.3.707)

Galantino-Homer HL, Florman HM, Storey BT, Dobrinski I \& Kopf GS 2004 Bovine sperm capacitation: assessment of phosphodiesterase activity and intracellular alkalinisation on capacitation-associated protein tyrosine phosphorylation. Molecular Reproduction and Development 67 487-500. (doi:10.1002/mrd.20034) 
van Gestel RA, Brewis IA, Ashton PR, Helms JB, Brouwers JF \& Gadella BM 2005a Capacitation-dependent concentration of lipid rafts in the apical ridge head area of porcine sperm cells. Molecular Human Reproduction 11 583-590. (doi:10.1093/molehr/gah200)

van Gestel RA, Helms JB, Brouwers JFHM \& Gadella BM 2005b Effects of methyl- $\beta$-cyclodextrin-mediated cholesterol depletion in porcine sperm compared to somatic cells. Molecular Reproduction and Development 72 386-395. (doi:10.1002/mrd.20351)

Goldberg AP, Lim A, Kolar JB, Grundhauser JJ, Steinke FH \& Schonfeld G 1982 Soybean protein independently lowers plasma cholesterol levels in primary hypercholesterolemia. Atherosclerosis 43 355-368. (doi:10.1016/0021-9150(82)90035-1)

González-Fernández L, Macías-García B, Velez IC, Varner DD \& Hinrichs K 2012 Calcium-calmodulin and $\mathrm{pH}$ regulate protein tyrosine phosphorylation in stallion sperm. Reproduction 144 411-422. (doi:10.1530/REP12-0067)

Harayama H, Miyake M, Shidara O, Iwamoto E \& Kato S 1998 Effects of calcium and bicarbonate on head-to-head agglutination in ejaculated boar spermatozoa. Reproduction, Fertility, and Development $\mathbf{1 0}$ 445-450. (doi:10.1071/RD98124)

Harayama H, Magargee SF, Kunze E, Shidara O, Iwamoto E, Arikawa S, Miyake M, Kato S \& Hammerstedt RH 1999 Changes in epididymal protein anti-agglutinin on ejaculated boar spermatozoa during capacitation in vitro. Reproduction, Fertility, and Development 11 193-199. (doi:10.1071/RD99056)

Harayama H, Miyake M \& Kato S 2000 Role of cyclic adenosine $3^{\prime}, 5^{\prime}$-monophosphate and serum albumin in head-to-head agglutination of boar spermatozoa. Reproduction, Fertility, and Development 12 307-318. (doi:10.1071/RD00030)

Harrison RP, Mairet B \& Miller NA 1993 Flow cytometric studies of bicarbonatemediated $\mathrm{Ca}^{2+}$ influx in boar sperm populations. Molecular Reproduction and Development 35 197-208. (doi:10.1002/mrd.1080350214)

Iritani A \& Niwa K 1977 Capacitation of bull spermatozoa and fertilization in vitro of cattle follicular oocytes matured in culture. Journal of Reproduction and Fertility 50 119-121.

Kenney RM, Bergman RV, Cooper WL \& Morse GW 1975 Minimal contamination techniques for breeding mares: techniques and preliminary findings. Proceedings of the American. Association of Equine Practitioners 327-336.

Leahy T \& Gadella BM 2011 Sperm surface changes and physiological consequences induced by sperm handling and storage. Reproduction 142 759-778. (doi:10.1530/REP-11-0310)

LeFrapper MS, Walston BS \& Whistant CS 2010 Comparison of various extenders for storage of cooled stallion spermatozoa for 72 hours. Journal of Equine Veterinary Science 30 200-204. (doi:10.1016/j.jevs.2010.02.007)

Lu Y, Huo R, Yuan Y, Li J, Shi Q \& Sha J 2006 Human testicular protein NYDSP16 is involved in sperm capacitation and the acrosome reaction. Fertility and Sterility 86 1228-1234. (doi:10.1016/j.fertnstert.2006.05.025)

McPartlin LA, Littell J, Mark E, Nelson JL, Travis AJ \& Bedford-Guaus SJ 2008 A defined medium supports changes consistent with capacitation in stallion sperm, as defined by increases in protein tyrosine phosphorylation and high rates of acrosomal exocytosis. Theriogenology 69 639-650. (doi:10.1016/j.theriogenology.2007.11.016)

McPartlin LA, Visconti PE \& Bedford-Guaus SJ 2011 Guanine-nucleotide exchange factors (RAPGEF3/RAPGEF4) induce sperm membrane depolarization and acrosomal exocytosis in capacitated stallion sperm. Biology of Reproduction 85 179-188. (doi:10.1095/biolreprod.110.085555)

Mukherjee AB \& Cohen MM 1970 Development of normal mice by in vitro fertilization. Nature 228 472-473. (doi:10.1038/228472a0)

Nagai T, Takahashi T, Masuda H, Shioya Y, Kuwayama M, Fukushima M, Iwasaki S \& Hanada A 1988 In vitro fertilization of pig oocytes of frozen boar spermatozoa. Journal of Reproduction and Fertility 84 585-591. (doi:10.1530/jrf.0.0840585)

Nixon B, Bielanowicz A, McLaughlin EA, Tanphaichitr N, Ensslin MA \& Aitken RJ 2009 Composition and significance of detergent resistant membranes in mouse spermatozoa. Journal of Cellular Physiology $\mathbf{2 1 8}$ 122-134. (doi:10.1002/jcp.21575)

Nixon B, Bielanowicz A, Anderson AL, Walsh A, Hall T, McCloghry A \& Aitken RJ 2010 Elucidation of the signaling pathways that underpin capacitation-associated surface phosphotyrosine expression in mouse spermatozoa. Journal of Cellular Physiology 224 71-83.
Nixon B, Mitchell LA, Anderson AL, McLaughlin EA, O'Bryan MK \& Aitken RJ 2011 Proteomic and functional analysis of human sperm detergent resistant membranes. Journal of Cellular Physiology 226 2651-2665. (doi:10.1002/jcp.22615)

Palmer E, Bezard J, Magistrini M \& Duchamp G 1991 In vitro fertilization in the horse. A retrospective study. Journal of Reproduction and Fertility. Supplement 44 376-384.

Parks JE \& Lynch DV 1992 Lipid composition and thermotropic phase behavior of boar, bull, stallion and rooster sperm membranes. Cryobiology 29 255-256. (doi:10.1016/0011-2240(92)90024-V)

Pommer AC, Rutllant J \& Meyers SA 2003 Phosphorylation of protein tyrosine residues in fresh and cryopreserved stallion spermatozoa under capacitating conditions. Biology of Reproduction 68 1208-1214. (doi:10.1095/biolreprod.102.011106)

Purdy PH \& Graham JK 2004 Effect of adding cholesterol to bull sperm membranes on sperm capacitation, the acrosome reaction, and fertility. Biology of Reproduction 48 36-45.

Rathi R, Colenbrander B, Bevers MM \& Gadella BM 2001 Evaluation of in vitro capacitation of stallion spermatozoa. Biology of Reproduction 65 462-470.

Rathi R, Colenbrander B, Stout TAE, Bevers MM \& Gadella BM 2003 Progesterone induces acrosome reaction in stallion spermatozoa via a protein tyrosine kinase dependent pathway. Molecular Reproduction and Development 64 120-128. (doi:10.1002/mrd.10216)

Reid AT, Lord T, Stanger SJ, Roman SD, McCluskey A, Robinson PJ, Aitken RJ \& Nixon B 2012 Dynamin regulates specific membrane fusion events necessary for acrosomal exocytosis in mouse spermatozoa. Journal of Biological Chemistry 287 37659-37672. (doi:10.1074/ jbc.M112.392803)

Rodriguez H, Torres C, Valdes X, Guerra H, Pastor LM, Maccallini G \& Bustos-Obregon E 2001 The acrosomic reaction in stallion spermatozoa: inductive effect of the mare preovulatory follicular fluid. Biocell $\mathbf{2 5}$ 115-120.

Shadan S, James PS, Howes EA \& Jones R 2004 Cholesterol efflux alters lipid raft stability and distribution during capacitation of boar spermatozoa. Biology of Reproduction 71 253-265. (doi:10.1095/biolreprod.103.026435)

Signorelli J, Diaz E \& Morales P 2012 Kinases, phosphatases and proteases during sperm capacitation. Cell and Tissue Research 349 765-782. (doi:10.1007/s00441-012-1370-3)

Towbin H, Staehelin T \& Gordon J 1979 Electrophoretic transfer of proteins from polyacrylamide gels to nitrocellulose sheets: procedure and some applications. PNAS 76 4350-4354.

Visconti PE, Bailey JL, Moore GD, Pan D, Olds-Clarke P \& Kopf GS 1995a Capacitation of mouse spermatozoa. I. Correlation between the capacitation state and protein tyrosine phosphorylation. Development 121 1129-1137.

Visconti PE, Moore GD, Bailey JL, Leclerc P, Conners SA, Pan D, Olds-Clarke P \& Kopf GS 1995b Capacitation of mouse spermatozoa. II. Protein tyrosine phosphorylation and capacitation are regulated by a cAMP-dependent pathway. Development 121 1139-1150.

Visconti PE, Ning X, Fornés MW, Alvarez JG, Stein P, Connors SA \& Kopf GS 1999 Cholesterol efflux-mediated signal transduction in mammalian sperm: cholesterol release signals an increase in protein tyrosine phosphorylation during mouse sperm capacitation. Developmental Biology 214 429-443. (doi:10.1006/dbio.1999.9428)

Whittingham DG 1968 Fertilization of mouse eggs in vitro. Nature 220592. (doi:10.1038/220592a0)

Yanagimachi R 1994 Mammalian fertilization. In The Physiology of Reproduction, Eds E Knobil \& JD Neil; second edition pp 189-317. New York: Raven Press.

Zhang JJ, Muzs LZ \& Boyle MS 1990 In vitro fertilization of horse follicular oocytes matured in vitro. Molecular Reproduction and Development 26 361-365. (doi:10.1002/mrd.1080260411)

Received 19 August 2013

First decision 18 October 2013

Revised manuscript received 21 October 2013

Accepted 5 November 2013 